\title{
Over 1,000 Years of Contact Between Arabic and the Eastern and Southern African Languages: A Case Study of Kiswahili and Setswana
}

\author{
Herman M. Batibo \\ Department of African Languages and Literature, University of Botswana, Gaborone, \\ Botswana
}

Tel: 267-355-2638Ｅ-mail: batibohm@mopipi.ub.bw

\author{
Received: August 2, 2018 Accepted: September 28, 2018 Published: October 1, 2018 \\ doi:10.5296/elr.v4i2.13729 URL: https://doi.org/10.5296/elr.v4i2.13729
}

\begin{abstract}
Arab travellers and traders along the eastern African coast, more than 1000 years ago, were the first Arabic speaking people to bring Arabic language in contact with the other African languages in eastern and later southern Africa. Over the years, Arabic gained a lot of influence in the region. The impact of Arabic can be seen, especially in old scripts, loanwords, Arabic accents and sound features in some of the local languages.

This article examines the nature and extent of contact situations between Arabic and two languages, namely Kiswahili, spoken in eastern Africa, and Setswana, spoken in southern Africa. The study is based on the Language Contact Theory, which states that the nature, length and intensity of language contact are the key factors determining the linguistic and sociolinguistic processes that take place. Contact between languages could be either direct or indirect. The main argument of the study is that the extent of influence of a language on another depends not only on the nature of contact, but also, and mainly, on the length and intensity of contact. The paper highlights the domains in which elements of Arabic origin have infiltrated or been adopted in these languages.
\end{abstract}

Keywords: Language contact, Language expansion, Language diffusion and language borrowing

\section{Introduction}

This article examines how Arabic came into contact with the languages of eastern and southern Africa, particularly Kiswahili and Setswana, as case studies. The contact took place for at least 1,000 years with various degrees of intensity. Arabic contact with the languages of eastern and southern Africa began over 1,000 years ago through Arab travellers and traders 
along the eastern coast and later in the interior as well as the southern parts of Africa Freeman-Grenville, (1962). Of course, one needs to mention that other groups had also come into contact with the eastern coast of Africa, such as the Persians and Chinese.

The main aim of the study is to examine the nature and extent of contact between Arabic and two languages, namely Kiswahili spoken in eastern Africa and Setswana, spoken in Southern Africa. These languages represent the two categories of languages in Africa in relation to Arab influence namely those which had direct Arab influence, such as Kiswahili, and those which had indirect Arab influence, such as Setswana.

Section one provides the introduction to the study. It highlights the status and position of Arabic as the second most widespread language in Africa, after Peul, and demographically the most dominant. Then section two discusses the theoretical framework which the study has adopted. Section three looks at the methods used in data collection. Then section four outlines the way the first Arab travelers came to the eastern African coast, followed by section five which highlights how Arabic came into contact with the speakers of a language which later became Kiswahili. Section seven discusses the nature and extent of contact between Arabic and Kiswahili, followed by section eight which describes the nature and extent of contact between Arabic and Setswana. Then section nine outlines the southern African features in Kiswahili, followed by section ten, which marks the conclusion of the study.

\section{Theoretical Framework}

The study is based on the Language Contact Theory, which states that the nature, length and intensity of language contact are the key factors determining the linguistic and sociolinguistic processes that take place (Kelechukwu, 20013; Nurse, 2000; Thomason \& Kaufmann, 1988). The model recognizes two major types of contact, namely direct and indirect contact.

The direct type of language contact, takes place in three forms. Such forms of contact usually cause far-reaching consequences in terms of lexical borrowing, adoption of structural elements, or sociolinguistic processes, like language shift or language endangerment. The three forms of contact are: Interactive contact, which takes place when two or more languages are adjacent to each other. The effect of this form of contact will depend on the period of contact, nature of contact and intensity of contact. The second form of contact is the integrative one. In this type, a small group of a language community decides to settle in the middle of a large and powerful community. In this case, the small group will be overwhelmed and may be absorbed or integrated into the larger community. This type of contact has been called suicide contact by Dorian (1977). The third type of contact is the expansive one, in which a large and powerful group expands into areas in which weaker groups inhabit. This is the case of Arabic expansion into the Maghreb region and their penetration along the coast and into the interior of eastern Africa (Freeman-Grenville, 1962).

On the other hand, indirect contact, is the second type, according to Batibo (2009), it can take place in two forms. The first form is diffusional contact. Such contact involves a lexical item, usually an object of socio-economic value, which diffuses over a large geographical area. The original word and meaning associated with the object will diffuse with it. For example the word for knife in Portuguese -sio (Rombi, 1989) has diffused over a large geographical area in eastern and southern Africa and has been adopted in different forms, sometimes with a 
slight change in meaning. Often words diffuse without the presence of the speakers of the original language in the area. That is why the process is known as indirect contact.

The second form of indirect contact is when a language influences two languages, which are spoken far apart from each other. Such indirect contact is known as parallel contact. For example both Kiswahili, spoken in eastern Africa, and Wolof, spoken in north-west Africa, have words like shetani (devil), ngamia (camel) and dini (religion). Such lexical identity is not due to common origin, but because both languages have borrowed these words from the same source, namely Arabic (Batibo, 1984, 11985).

\section{Method of Data Collection}

This study is based on documentary research. The data for this study were collected from historical and etymological sources. Also some of the information was obtained through personal observations and experiences as a Kiswahili speaker and through informal interviews with other scholars.

\section{The Arrival of the First Arab Travellers and Traders in Eastern Africa}

The first Arabs to come to eastern Africa were mainly travellers and adventurers. The two prominent among them were Al-Masudi $\left(10^{\text {th }}\right.$ Century) and Ibn-Battuta ( $14^{\text {th }}$ Century), who have been described as among the first Arab travellers to visit the eastern African coast Freeman-Grenville, 1962; Polomé, 1967; Whiteley, 1969). The other Arabs who came later became interested in trade and commerce. They brought clothing, porcelain ware and glass beads to exchange for ivory, hides, gold and mangrove poles.

\section{First Arab Contact With Kiswahili Language}

As Arab trade along the eastern coast of Africa intensified, particularly towards the $18^{\text {th }}$ Century, the Arab traders identified a language at the mouth of river Sabaki, in present Kenya. The speakers of this language were farmers but also fishermen who helped the Arabs as contact people or middlemen in dealing with other populations who spoke many languages, some of which were highly related (Nurse \& Spear, 1985/2017).

The Arabs called these coastal settlements sawahil [sawa:hil] (plural of sahil [sa:hil] "coast". By the $11^{\text {th }}$ century the name sawahil became associated with the local language, which the Arabs used as a go-between with other groups. It is certain that, as in many other cases, that language had its name. But the name was eclipsed by the name given by foreigners who had become dominant on the eastern African coast. The other Sabaki valley languages which were closely related to these languages, which was now known as Kiswahili, were Digo, Pokomo, Giryama, and Ilwana (Hinnebusch, 1981; Moehlig, 1981; Nurse \& Spear, 1985/2017).

As the Arab trade and influence grew along the eastern coast so did Kiswahili (the name was given the prefix ki-, as all names of languages are designated in the Bantu nominal system) also expanded along the eastern coast, as a lingua franca. Arab trade spread along the coast for over 1500 kilometres from Brava in present-day Somali through other trading ports namely, Brava, Kisimayu (Somalia), Malindi, Kilindi, Lamu, Mombasa (Kenya), Pemba, Saadani, Bagamoyo, Zanzibar, Kilwa (Tanzania), Quelimane [Kilimani] and Sofala (Mozambique). Kiswahili did not only become the lingua franca of the eastern African coast between the Arab traders and the local populations, but also adopted many Arabic linguistic 
features, such as vocabulary, sounds and even accents. Moreover, it also acquired some Arabic cultural elements, including Islamic expressions, since most of the coastal town populations had converted to Islam. The vocabulary items that Kiswahili had adopted from Arabic were mainly in trade, commerce, counting, interaction, dress, prayer and so on.

\section{Kiswahili Expansion Inland and in the South of Africa Through Contact With Arabs}

Arab trade along the eastern coast lasted for more than seven centuries. During the $18^{\text {th }}$ and $19^{\text {th }}$ centuries, when the Busaidi Sultanate established its authority on the coast and transferred its capital to Zanzibar, Arab trade expanded into the interior of eastern and southern parts of Africa. Another item had been added, namely the slave trade to the Persian Gulf and India, which became, with ivory, the most important focal point. Arab-led caravans, accompanied by Kiswahili speaking guides, went into the hinterland in search of slaves, but also ivory, hides and wood. Nyamwezi traders operating from the interior helped to turn these trade routes into corridors. As a byproduct, Arab culture and a new religious belief, namely Islam, spread along the trade routes, and Kiswahili emerged as the traders' lingua franca. In this case, Arab influence in the hinterland became indirect, that is through another medium. Kiswahili was able to spread easily as a lingua franca because of its similarity in structure and vocabulary with the other Bantu languages in those trading areas.

When the Omani (Busaidi family) Sultan moved to Zanzibar in the early 19th century, Arab presence in the eastern coast of Africa intensified. Arabic was the language of the Sultanate. Kiswahili language was written in Arabic orthography. Many Arabic loanwords were adopted in a range of domains, such as administration, law, trade, commerce, religion, culture, education and food. Speaking Kiswahili with an Arabic accent or mannerism was seen as a sign of civilization "usta-arab/ustaarabu" (state of half-arab). Hence some Arabic sounds were adopted into Kiswahili.

\section{The nature and extent of contact between Arabic and Kiswahili}

\subsection{Nature of Contact Between Arabic and Swahili}

The type of contact between Arabic and Kiswahili was the expansive one, which also depends on time lapse of contact, nature of contact and intensity of contact. In the case of Kiswahili, the contact took place over a long stretch of time, namely over 1000 years, with intense consequences, as it involved far-reaching expansion along the eastern coast and then constant interaction with Kiswahili, when the two were used side by side for over 1000 years in most of the domains.

Usually when contact is slight or lasts for a short period, without much impact, very few features will be adopted by local language from the intruding language. Usually only a few lexical items from the relevant domain may be borrowed, such as merchandise, food items, clothes or ornaments. In the case of Swahili, which had a direct contact by the Arabs over a period of over 1000 years, with dense and protracted interaction, the amount of borrowing of Swahili from Arabic has been very far reaching, as it has taken place not only in all aspects of the language, but also in cultural and autonymic identity.

\subsection{Arabic Language Borrowings inKiswahili}

The Arabic languages borrowings in Kiswahili are found at all linguistic levels, namely phonology, morphology, syntax and the lexicon. Examples are given below: 


\section{Macrothink}

\section{a) Arabic sound features in Kiswahili}

Given the long contact between Arabic and Kiswahili, a significant number of new vocabulary items has entered the language, with sounds which were not part of the Kiswahili sound system. These sounds include: th [ found in words such as thelathini (thirty), thamani (value) and thumuni (half a shilling), dh $[\lambda]$, found in words, such as dhana (concept, thought) dharau (despise), dhiki (poverty, helplessness); gh [ $\square]$, found in words like gharama (cost), ghafla (suddenly) and ughaibuni (in a foreign land).

Other Arabic sounds appear when speakers decide to speak with an Arabic accent (thought by many to be more sophisticated). Hence the pharyngeal sound [ $\square]$ may be used instead of the usual glottal $[\mathrm{h}]$ in a word like habari (news) or the velar fricative $[\mathrm{x}]$, instead of the usual glottal [h] (Johnson, 1986; TUKI, 1981).

Moreover, Kiswahili had only the lateral [1], like many other Bantu languages. But, after the heavy influx of Arabic and English words containing the sound [r], this sound was also added to the Kiswahili sound system. The Arabic orthography, which was very common in the old Kiswahili scripts, especially in the coastal area, is now used very rarely in Kiswahili writing system except in Koranic scripts, particularly by the older generation.

\section{b) Arabic morphological features in Kiswahili}

Although Kiswahili morphology is generally typically Bantu, there has been a new development morphemic forms, due to Arabic influence. The most typical of this is the presence of a $\sim^{-}$(zero) prefix before adjectives of Arabic stems of origin. Hence, adjectives of Arabic origin are distinguished from adjectives of Bantu origin, because the former do not have visible prefixes, as seen in examples (1) and (2) below:

1) Kiswahili adjectives of Arabic origin

viatu bora (good quality shoes)

viatu safi (clean shoes)

viatu lainu (soft shoes)

viatu ghali (expensive shoes)

2) Kiswahili adjectives of Bantu origin

viatu vi-baya (bad shoes)

viatu vi-zuri (nice shoes)

viatu vi-kubwa (big shoes)

viatu vi-dogo (small shoes)

\section{c) Arabic syntactic features in Kiswahili}

Like most other Bantu language, Kiswahili language did not have many conjunctive words, as traditionally sentences in Bantu languages were narrative involving simple succession of clauses. When a subordinate clause had to follow a main sentence, usually the two sentences were juxta-positioned or had infinitival paraphrases, as in (3) below: 


\section{Macrothink \\ Education and Linguistics Research \\ ISSN 2377-1356 \\ 2018, Vol. 4, No. 2}

3) Traditional subordination in Kiswahili

Nimekuja nikuone (I have come so as to see you)

Nimekupiga kwa kuwa wewe mjinga (I have beaten you because you are foolish)

Nimekuja. ujue, sikai sana (I have come. But know that I am not staying long).

Amefika, mgonjwa (He has arrived, but he is sick)

With the use of conjunctives of Arabic origin, it became much easier to connect clauses, as in

(4) below:

4) Nimekuja ili nikuone (I have come so as to see you)

Nimekupiga kwa sababu wewe mjinga (I have beaten you because you are foolish)

Nimekuja. Lakini ujue, sikai sana (I have come but know that I am not staying long"

Amefika, ila mgonjwa (he has arrived, but he is sick).

d) Arabic loanwords in Kiswahili

Due to the long direct contact between Arabic and Kiswahili, the latter has adopted many loanwords, in practically all domains. The domains in which Arabic loanwords are found in abundance are in the following fields:

5) domains in which Arabic origin loanwords are abundant

i) Administration and rule

utawala (rule, governance)

madaraka (responsibilities)

mfalme (king)

malkia (queen)

mamlaka (authority)

waziri (minister)

raisi (president)

katibu (secretary)

rushwa (corruption)

uhuru (independence)

raia (citizen)

ii) Religion and ethics

dini (religion)

sala (prayer)

kusali (to pray)

msikiti (mosque)

kanisa (church)

imani (faith)

matumaini (hope)

neema (grace)

shetani (devil) 


\section{Macrothink}

malaika (angel)

utii (obedience)

maadili (good conduct)

sadaka (sacrifice)

baraka (blessings)

iii) Law and order

sheria (law)

hukumu (verdict)

mahakama (court of law)

hakimu (magistrate)

kushitaki (to accuse)

rufaa (appeal)

wakili (advocate)

mashahidi (witness)

samehe (pardon)

madai (claims)

madeni (debts)

iv) Culture and way of life

utamanduni (culture)

mila (customs)

desturi (tradition, way of life)

kufariki (to die)

binamu (cousin)

kuboresha (to improve)

bora (better, good quality)

dharau (despise)

kuridhika (to be satisfied)

maadili (good conduct)

heshima (respect)

huruma (pity)

kudhuru (injure)

harusi (wedding)

v) Education and teaching

mwalimu (teacher)

hadithi (story, legend)

hekima (wisdom)

elimu (education) 


\section{Macrothink}

kufaulu (to pass)

kurudia (to repeat a class or lesson)

wizara (ministry)

mitaala (curriculum development)

majukumu (responsibility)

adhabu (punishment)

zawadi (reward)

kitabu (book)

sura (chapter)

mtihani (examination)

vi) Trade and commerce

biashara (business)

fedha (money)

mhasibu (accountant)

mhazini (treasure)

hazina (treasury)

hasara (loss)

faida (profit)

riba (interest)

dhuluma (injustice)

kudhulumu (to swindle, treat unjustly)

mabishano (argument, bargain)

bidhaa (goods)

kusafirisha (to transport)

The above examples are the most common domains in which words of Arabic origin are found in Kiswahili. In recent years, many technical and scientific words have entered into Swahili. Many of them are from English, but a few are from Arabic. In fact, many of these words of Arabic origin have synonyms of Bantu origin. In some cases, the Bantu word has been replaced by that of Arabic origin.

Although most basic vocabulary in Kiswahili is of Bantu origin (given that Kiswahili is a Bantu language), some words of Arabic origin have penetrated in this category of vocabulary. Most of these words are associated with taboo, indecent or unpleasant phenomena, such as meanings depicting death, burial, injury or private parts and so on. Some of these words are shown in (6) below:

(6) Basic vocabulary of Arabic origin

kufariki (to die)

maiti (corpse)

mauti (death)

jeraha (bad injury) 
damu (blood)

kaburi (tomb)

dhakari (penis)

kujamiiana (to have sex)

kubusu (to kiss)

kubarehe (to come to puberty

kutabasamu (to smile)

Like other Bantu languages, counting was usually done by fingers from one to five. Then both hands were combined to make ten. The numbers from six to nine were a problem in many Bantu languages, as they had to combine numbers, such as four plus four to make eight (nne na nne > nane (eight, in Kiswahili). Kiswahili had to borrow the numbers 6, 7 and 9 from Arabic, namely sita, saba and tisa respectively.

\section{The Nature and Extent of Contact Between Arabic and Setswana}

\subsection{The Nature of Contact}

While contact between Arabic and Kiswahili was intense, given that it was not only direct, but also extensive and lasted for a long period of time, the contact between Arabic and Setswana was very slight. This is because it was indirect, through intermediary languages. It involved only the trading domain, mainly in the last part of the $1^{\text {st }}$ millennium (Denbow AND Denbow (1989), Huffman $(1989,2015)$. This contact did not last for a long period of time, as in the case of Kiswahili in eastern Africa. Hence, only a few items of vocabulary were involved, especially in the trading domain.

The contact between Arabic and Setswana, was not direct, but indirect, through the Arab trade which had flourished over the eastern coast from Brava in present-day Somalia, down to Quelimane and Sofala, in present-day Mozambique, the Arabs were able to sell items of value, such as cloths, glass beads and ornaments in exchange for goods from the interior, such as wood, ivory, salt, hides and later, slaves (Denbow and Denbow (1989). Some Batswana speakers were involved in this long-distant trade, between the coast and the hinterland. In fact, this explains the existence of the words leatle (sea) and sebabili (sea spirit) in Setswana (Cole, 1995).

Thus, Arabic words managed to enter Setswana through this process of diffusion, just as some of these words have entered many of the Southern African languages. This process of adoption is known as diffusional contact, which is indirect.

8.2 Diffusion of the Arabic Word - maal

The Arabic word which has diffused into the southern African region extensively is the word maal (piece of silver) in old Arabic. This word was brought first in eastern Africa, where its meaning became "money, goods, wealth". The Kiswahili word is mali (since a final vowel has to be added in a Bantu language). The word then diffused into southern Africa through the Arab posts in Quelimane and Sofala. It took different shapes depending on the receiving language, as shown in (7) below:

7) The adoption of the Arabic word maal in southern Bantu languages

madi (money), Setswana 
mari (money), IchiShona

madi (money), Sesotho

imari (money), IsiZulu

madi (money), Sepedi

imari (money), IsiXhosa

This word was probably introduced in southern Africa, when trade between locals and foreigners was intensified. Most of this trade was carried out through exchange of goods of value. Hence, the loanword mali/madi must have meant "goods of value", like in Kiswahili (Matumo, 1993). Later beads were used as currency is southern Africa. The word mali/madi was later used to refer to the currency itself, as means of exchange of goods and wealth. One should not confuse the origin of the word madi (money) in Setswana (from maal in Arabic) and the homonym madi (blood), which is a typically Bantu word (*ma-gadi (blood) > ma-adi $>$ madi).

\subsection{Other Words of Arabic Origin}

One Arabic word, which appears to have diffused into Setswana is the term for "glass beads". Beads were considered to be items of value and had been brought by the Arabs and traded in the interior together with cloth and ornaments in exchange for ivory, hides, and even slaves and gold (Huffman, 2015; Pollard \& Kinyera, 2017).

The word for "glass bead", which was brought into Kiswahili from old Arabic darhamu and adopted in Kiswahili as dalama, acquired the prefix n- (ndalama), because of being a borrowed item (which normally would be classified in classes 9/10, with $n$-prefix). The form of the word became interchangeable with ndarama, given that in old Swahili the sounds [1] and $[\mathrm{r}$ ] were interchangeable (Batibo, 1985) This word was diffused into Setswana as talama "bead, necklace". Usually, the [nd] sound has become [t] in Setswana.

Another word with the same meaning is misbaha (prayer beads) in Arabic, which is presumed to have diffused into Setswana in the early millennium (Morton, p.c). This word has been adopted as sebaga (beads) in current Setswana. The process of adapting the word to Setswana sound structure involved the truncation of the first syllable [mi] and the insertion of the vowel [e] (or [ $[$ ] $]$ ), to create the noun prefix [se-] (Class 7), used for "man-made objects", among other senses. Then, the sound $[\mathrm{h}]$ could have been replaced by the velar fricative $[\mathrm{x}]$.

There are not many words of Arabic origin in Setswana, partly because of the distance of Setswana language from spheres of influence of Arabic in the eastern coast and partly because of the new foreign languages, namely English and Afrikaans, which may have replaced the originally Arabic words.

It is possible that other words of Arabic origin were introduced into Setswana during the time of contact between the eastern part of what is now Botswana and the coast. This explains why Setswana has words for sea (leatle), sea-spirit (sebabili) and sea-weed (bolele) (Matumo, 1993). In fact, according to Denbow and Denbow (1989), there were a number of mines in what is now Botswana, including the salt mines in the Makgadikgadi Pans, which had attracted traders from the coast.

Words of Arabic origin which could have diffused in Setswana have probably been replaced 
by English and Afrikaans words in more recent years. In fact, even the word madi (money) in Setswana is gradually being replaced by an Afrikaans word chelete in the eastern dialects of Setswana. One reason why only few words managed to diffuse into Setswana is the distance between what is now Botswana and the eastern coast. The distance is at least 2,000 kilometres from Sofala, the closest Arab post.

\section{Southern African Linguistic Features in Kiswahili}

The piece of evidence that at one time there was protracted contact between southern Africa and eastern Africa, presumably through trade, is the presence of southern African linguistic features in Kiswahili.

\subsection{The Presence of the -ana Suffix in Kiswahili}

One of the innovations which Bantu languages made when they migrated to southern Africa through the Zambezi valley in AD 300, is the use of -ana as a suffix to replace the $k a-/ t u$ - or $k i-/ v i$ - prefixes for diminutive nouns. For example: in Setswana, podi (goat), but potsana [podi-ana] (kid). In Kiswahili, the diminutive prefix is still used, for example: mtoto (child), but ki-toto (infant). Kiswahili has many diminutive words with suffix - ana, as exemplified in (8):

mtu (person) $>$ mtwana (slave, small person)

mlungu (European, [Olf form]) > muungwana (gentlemen, [small European])

msiki (maiden [Old form) $>$ msichana (girl)

mvule (youth [Old form] $>$ mvulana (boy)

The diminutive suffix - ana is not found in the other eastern African Bantu languages. Noun classes $12 / 13$ and $7 / 8$ are used are usually used to express this notion.

\section{Conclusion}

This study was concerned with the contact between the Arabic language and the Bantu languages of eastern and southern Africa. Two languages were chosen as case studies, namely Kiswahili, a major language in eastern Africa, and Setswana, the most extensively spoken language in southern Africa. The study has shown that the two languages did not have the same impact and duration of contact. While Kiswahili has had a direct, intense and prolonged interactive contact with Arabic, Setswana had an indirect, slight and relatively shorter period contact. In fact, the contact with Setswana was not interactive but diffusional, evidence that where Setswana was spoken it is likely at the tail-end of trading connections with multiple intermediaries between the east coast and the interior.

Hence the paper strengthens the primary assumption of the study, namely that the extent of influence of a language on another depends not only on the nature of contact but also, and mainly on the length and intensity of contact. Thus, Arabic managed to penetrate almost all domains of Kiswahili as well as all aspects of grammar and vocabulary. Because of this intense penetration, some scholars like Le Page, 1964; Zawawi, 1990) have described Swahili as an Arabic Pidgin or Creole. But the fact that the core aspects of the language have remained typically Bantu, such as basic vocabulary and grammatical structure, leads to the conclusion that Swahili should be considered a typically Bantu language (Polomé, 1967; Whiteley, 1969). 


\section{Macrothink}

What is peculiar about Kiswahili is its flexibility in accommodating foreign features like diphthongs, guttural sounds, consonant clusters and semi-domesticated word structures. On the other hand, Setswana has remained largely intact with fewer words of foreign origin, most of which are from English and Afrikaans. Only three words of Arabic origin were spotted in the language. Setswana has kept its faithfulness to Bantu language norms in sounds and structures.

Apart from the influx of Arabic vocabulary in Kiswahili, facilitating the possibility of synonyms, stylistic variation and specialization of terms in specific domains (Batibo, 1984), Kiswahili has also made it possible to have a good range of generic terms. It has often been remarked that Bantu languages normally, do not have generic words (Alexandre, 1967) but Kiswahili, thanks to Arabic adoptions, has now words like samani (furniture), vifaa (tools), umati (crowd of people), umma (public), jamaa (close relatives), nukshi (ornaments), sare (uniform), samaki (fish in general), umri (age), jinsia (gender), nyaraka (documents), halaiki (crowd), hesabu (accounts), jeshi (army) (Batibo, 1985).

\section{References}

Alexander, P. (1967). Langue et Langage en Afrique Noire. Paris Payot.

Batibo, H. M. (1984). The important contribution of Arabic to the development of Kiswahili. Islam Today, 1(2), 29-37.

Batibo, H. M. (1985). The growth of Kiswahili as a language of administration and education in Tanzania. In M. Putz (Ed.), Linguistic Inequality in Africa (pp. 57-80). Berlin: Mouton de Gruyter.

Cole, D. T. (1995). Dictionary of Setswana-English Names of Animals and Plants. Gaborone Botswana Society.

Denbow J. R., \& Denbow, J. (1989). Uncovering Botswana's Past. Gaborone: National Museum 4.

Dorian, N. C. The problem of the semi-speakers in language death. In W. Dressler, \& R. Wodak-Kodotter (Eds.). Language Death (pp. 23-32). Paris: Mouton Publishers.

Freeman-Grenville, S. P. (1962). The East African Coast: Selected Documents. Oxford: Clarendon Press.

Hinnebusch, T. J. (1981). Northern eastern Bantu. In T. Hinnebusch, D. Nurse, \& M. Mould (Eds.), Studies in the classification of eastern Bantu languages SUGIA. (Vol. 3). Hamburg: Bueske Verlag.

Huffman, T. N. (1989). Ceramics, settlement and late iron age migrations. African Archaeological Review, 7, 155-182. https://doi.org/10.1007/BF01116842

Huffman, T. N. (2015). Mapela, Mapungubwe and the origins of states in Southern Africa. The South African Archacological Bulletin., 70, 15-27.

Johnson, F. (1986). A Standard Swahili-English Dictionary. Nairobi: Oxford University Press.

Kelechukwu, U. Ihemere (ed.) (2013). Language Contact: A Multidimensional Perspective. Cambridge: Cambridge Scholars Publishing

Le Page, R. (1964). The National Language Question: Linguistic Problems of Newly 
Independent States. New York: Oxford University Press.

Matumo, Z. I. (1993). Setswana- English-Setswana Dictionary. Gaborone: Macmillan Botswana.

Moehlig, W. (1979). Stratification of the history of the Bantu languages. SUGIA, 3, 251-317.

Nurse, D. (1988). The diachronic background to the language communities of Southern Tanzania. SUGIA, 9, 15-115.

Nurse, D. (2000). Inheritance, Contact and Change in Two East African Languages. (Language Contact in Africa 4). Koeln: Ruediger Koeppe Verlag.

Nurse, D., \& Spear, T. (1985/2017). The Swahili: Reconstructing the History and Language of an African Society, 800-1,500. Pennsylvania: University of Pennsylvania Press. https://doi.org/10.9783/9781512821666

Pollard, E., \&Kinyera, O. C. (2017). The Swahili coast and the Indian Ocean Trade Patterns in the $7^{\text {th }}-10^{\text {th }}$ centuries C.E in Journal of Southern African Studies, 43(5), 927-947. https://doi.org/10.1080/03057070.2017.1345266

Polomé E. (1967). A Handbook of Swahili Grammar. Washington Centre of Applied Linguistics.

Rombi, M-F. (1989). Le Swahili et ses Limites. Paris: Editions Recherches sur les civilisations. Cahier No. 5.

Taasis ya Uchunguza wa Kiswahili (TUKI) (1981). Kamuzi ya Kiswahili Sanifu. Dar es Salaam: Oxford University Press.

Thomas, S. G., \& Kauffman, T. (1988). Language, Contact, Creolization and Genetic Linguistics. Berkeley: University of California Press.

Whiteley, W. H. (1969). Swahili: The Rise of a National Language. London: Methuen Press. Zawawi, S. (1990). Jifunze Kiswahili Chetu: Vol 2 Learn Our Kiswahili, Nairobi: African World Press.

\section{Copyright Disclaimer}

Copyright reserved by the author(s).

This article is an open-access article distributed under the terms and conditions of the Creative Commons Attribution license (http://creativecommons.org/licenses/by/3.0/). 